National Confidential Inquiry into Suicide and

\section{Homicide by People with Mental Illness}

LOUIS APPLEBY, JENNY SHAW and TIM AMOS a result, specific recommendations will be made on clinical practice and training. Inquiry questionnaires have been re-designed with these aims in mind.

\section{CASE IDENTIFICATION}

Comprehensive reporting is essential to the success of the Inquiry, and new systems of case identification have been introduced for both suicides and homicides.

For suicides in England and Wales, the system is an adaptation of one that has proved successful in research in Manchester (Dennehy et al, 1996) and that makes use of the official process of death notification and reporting. Following a coroner's inquest, the director of public health (DPH) in the deceased's district of residence is notified of the death by the local registrar. Over onethird of DPHs receive equivalent information from the Office for National Statistics. The Inquiry has arranged for DPHs to forward information on all suicides and probable suicides (open verdicts/deaths from undetermined cause). In an average district of 450000 people, there should be around four cases per month, so the amount of work for any one district is small.

By checking information on each case against records held by local mental health services and some specialist supra-district services, the Inquiry will identify those with a history of service contact in the year before death (this remains the main inclusion criterion for suicides) and the consultant psychiatrist whose team was involved. The latter will be asked to hold a multidisciplinary review of the case (many mental health teams already do so) and to complete a standard questionnaire.

The main disadvantages of the Inquiry's new methods are the delay of three to six months before most inquests, and the reliance on multiple sources of data (there are 105 health districts and nearly 200 trusts treating mental illness in England and Wales). The delay, however, is common to most suicide research and its problems are outweighed by the advantage of a uniform definition of suicide. In time, it may prove possible to receive initial details of all cases direct from a single central source (i.e. the Office for National Statistics), although this is not an immediate option. For Scotland and Northern Ireland, submission of cases from an equivalent central source, the General Register Office, is currently under discussion. 
For homicides in England and Wales the Inquiry will receive information on all cases of murder, manslaughter and infanticide from the Home Office Homicide Index. From these details the court where the case was tried will be identified. Inquiry staff will then collect further information from court records, in particular from the psychiatric reports which are prepared on all those charged with homicide. A similar system is being planned in Scotland and Northern Ireland.

These records will show whether there has been any previous contact with mental health services, and a questionnaire will be sent to the responsible consultant as in the suicide inquiry. The Inquiry will therefore collect psychiatric data on all homicides, and detailed clinical information on all those with a history of mental health service contact, whenever this occurred. Cases in which contact occurred less than a year before the homicide will remain identifiable within the total sample. Homicides followed by suicide will be detected through the suicide inquiry.

\section{INQUIRY DATA}

The new Inquiry questionnaires consist of 10 sections, covering the following: priority groups (as above); demographic information; psychiatric history; details of suicide/ homicide; in-patient suicides/homicides; suicides/homicides by out-patients, community patients and discharged patients; details of last contact; antecedents of suicide/ homicide; respondent's view on prevention; and a final section for comments and additional information. Similar questions are asked about suicides and homicides, although in addition the homicide questionnaire enquires about previous violence. The questionnaire takes about 20 minutes to complete.

The potential size of the suicide inquiry sample is over 1000 cases per year and it should be possible to gather information on important groups of patients that appear in

LOUIS APPLEBY, MD, JENNY SHAW, MRCPysch, TIM AMOS, MRCPsych, National Confidential Inquiry into Suicide and Homicide by People with Mental IIIness, Manchester M20 2EF

Correspondence: Professor L. Appleby, National Confidential Inquiry into Suicide and Homicide by People with Mental Illness, PO Box 86, Manchester M20 2EF

(First received 7 October 1996, accepted 7 November 1996)

only small numbers in most studies. The questionnaires have been constructed to identify these groups so that they can be studied separately and/or compared with the total sample. Examples include prisoners, diagnostic subgroups, people with a secondary diagnosis of substance misuse or personality disorder, people aged over 65 , and people referred to services urgently under Section 136 of the Mental Health Act. Similarly, in the homicide inquiry it will be possible to study many of these groups and to examine cases of infanticide separately, in addition to comparing patients with and without a history of violence. One section of both the suicide and homicide questionnaires places in chronological order events that may have indicated increasing risk, such as non-compliance, increased alcohol misuse or failed service contact. The information collected will be used to construct models of suicide or homicide, each with different opportunities for preventive intervention.

\section{DISSEMINATION OF FINDINGS}

The overall findings of the Inquiry are expected to be published in major reports, the first after two years of data collection, and a series of detailed papers is also planned. Most importantly, results will inform the development of training packages in the assessment and management of risk for front-line mental health staff from different disciplines, and provide the basis for recommendations on clinical practice. For example, we expect to advise on how the care programme approach can be used to prevent suicide more effectively, and on the development of guidelines on responding to non-attendance and non-compliance by highrisk patients.

The Confidential Inquiry represents a unique opportunity to collect detailed information about suicides and homicides by people with mental illness but its goals can be attained only if clinicians feel able to provide information frankly. We shall ensure the confidentiality of data submitted to the Inquiry. All data will be aggregated for analysis and no individual cases will be reported. We hope that, because we are seeking information after an inquest or a trial, the anxieties about disclosure that the legal process inevitably arouses will have subsided. Suicide and homicide by people with mental illness are sensitive subjects, but the aim of the Inquiry is to improve services, not to blame them.

\section{REFERENCES}

Bowden, P. (1995) Confidential inquiry into homicides and suicides by mentally ill people. A preliminary report on homicide. Psychiotric Bulletin, 1265-66.

Dennelyy 1., Appleby, L. Thomas, C., et el (1990) Casecontrol study of suicide by discharged psychiatric patients. British Medical Journal, 312. 1580.

House, A. (199) Homicides and suicides by mentally ill people. British Medical Journal, 312. 135-136.

Ritchile, J., Dick, D. \& Lingham, R. (1994) The Report of the Inquiry into the Core and Treotment of Christopher Clunis. London: Her Majesty's Stationery Office.

Steerine Committee of the Combdental Inquiry into Homidides and Sulcides by Mentally ill People (1994) A Preliminary Report on Homicide. London: Royal College of Psychiatrists on behalf of the Steering Committee.

- (1996) Report of the Confidential Inquiry into Homicides and Suicides by Mentally III People. London: Royal College of Psychiatrists on behalf of the Steering Committee. 